\title{
Indigenous knowledge: Africa's opportunity to contribute to global information content
}

\author{
Justin Chisenga \\ Department of Information Studies (Graduate Student) \\ Rand Afrikaans University, Auckland Park, South Africa \\ jchisenga@hotmail.com
}

Received: 1 June 2002

\begin{abstract}
This paper argues that harnessing, repackaging and providing access to Africa's indigenous knowledge systems using the World Wide Web infrastructure will present the people of Africa with an opportunity to make a major contribution to the development of the information content on the Web. This will also ensure that information consumers in Africa will have access to information content produced on the continent. Problems associated with the documentation of indigenous knowledge are highlighted, and the role of information professionals on the continent in ensuring that Africa's indigenous knowledge systems are widely disseminated over the Web is briefly discussed.
\end{abstract}

\section{Introduction}

Since 1995, access to the Internet and the World Wide Web has developed at a relatively faster pace than before on the African continent. All 54 countries and territories now have Internet access in their capital cities, and a growing number of them have points of presence in some of the secondary towns (Jensen, 2001). As of August 2001, it was estimated that Africa had around 4,15 million Internet users (NUA, 2001). In addition, various national governments, local and international non-governmental organisations (NGOs) and donor agencies are making an effort to implement projects that will ensure that more people on the continent have access to the Internet and Web facilities, for example through the use of telecentres. With the relatively accelerated development in information and communications technologies (ICTs) in Africa, increasingly access to the Internet no longer becomes an issue. The major issue now is access to appropriate information content on the Web.

Unfortunately, Africa's contribution to the global information content available on the Web is minimal. The Web content is entirely dominated by material produced in the United States, Europe and Asia. As a result, information consumers in Africa are on the receiving end of information being produced from outside the continent. Information for solutions to a large number of African problems and situations is sought and accessed on databases and electronic networks developed outside the continent. Some of the information available on the Web bears no relevance to the needs of the people of Africa. This is in spite of the fact that Africa produces a great deal of information and knowledge relevant to, and useful for, its environment. This being the case, there is an urgent need to ensure that information content from Africa is harnessed, repackaged and added to the global information infrastructure. It is in this context that some of the existing indigenous knowledge systems on the continent should be made available on the Web. This would contribute to the development of African content on the global information infrastructure.

\section{Defining indigenous knowledge}

Several terms are often used interchangeably to refer to indigenous knowledge, e.g. traditional knowledge, local knowledge, indigenous skill, indigenous technical knowledge, folk knowledge, peoples' science, rural people's knowledge, ethnoscience and cultural knowledge. In this paper, the terms "indigenous knowledge" (IK) and "indigenous knowledge systems" (IKSs) are used interchangeably to encompass all of the above terms.

What then is indigenous knowledge? Just as there are several terms referring to IK, there are also several definitions of the concept. For example, the World Bank (1998) defines indigenous knowledge as local knowledge that is unique to every culture and society. It is the basis for local decision making in agriculture, health, natural resource management and other activities. Indigenous knowledge is embedded in community practices, institutions, relationships and rituals. It is part of everyday life, such as herbal medicines and acupuncture. The Southern African Research and Documentation Centre (SARDC, n.d.) defines an IKS as "a body of knowledge and beliefs built by a 
group of people, and handed down generations through oral tradition, about the relationship between living beings and their environment. It includes a system of organisation, a set of empirical observations about the local environment, and a system of self-management that governs resource use".

Grenier (1998) defines IK as the unique, traditional and local knowledge existing within, and developed around, specific conditions of women and men indigenous to a particular geographic area. The International Institute of Rural Reconstruction (IIRR, 1996) defines IK as the knowledge that people in a given community have developed over time, and continue to develop. This knowledge is:

- based on experience

- often tested over centuries of use

- adapted to the local culture and environment

- dynamic and changing.

There are several examples of practices from around the world that have evolved from using indigenous practices. These include mixed cropping systems, water management systems, pastoral cattle movement, crop rotation methods, irrigation systems and the use of medicinal plants for people and livestock (Rouse, 1999).

Other major characteristics of IK are the following:

- It is not confined to tribal groups or the original inhabitants of an area, and it is not confined to rural people. Any community possesses IK - rural or urban, settled or nomadic, original inhabitants or migrants (IIRR, 1996).

- It is based on ideas, experiences, practices and information that have been generated either locally or elsewhere, and have been transformed by local people and incorporated into their way of life (Ina Hoi Riwa Foundation, 2000).

- It is expressed in local languages (Langill, 1999).

- It is difficult to transmit IK to those who do not share the language, tradition and cultural experience (SARDC, n.d.).

The discussion of IK in this paper is based on the definitions and characteristics of IK set out above, as they apply to the African environment and communities.

\section{Indigenous knowledge systems: endangered species}

Indigenous knowledge systems around the world, especially in the developing countries of Africa, Asia and Latin America, are at risk of becoming extinct. IKSs are threatened by modernisation, urbanisation and globalisation. Indigenous knowledge in most communities around the world is generally not documented; it is shared through traditional oral communication systems. It is "most commonly exchanged through personal communication and demonstration: from master to apprentice, from parents to children, from neighbor to neighbor, from priest to parish" (World Bank, 1998). Unfortunately, the traditional oral channels of communication are being disrupted and people no longer live in homogeneous community blocks (Kothari, 1995). Disruption of traditional communication systems is threatening the preservation of IK in most communities around the world.

In addition, modern education systems in developing countries do not have IK subjects or modules in their curricula. Therefore, IK is not being passed from one generation to another in schools. In most cases, modern education systems have been found to be anti-IK, and produce learners who rarely value IK as highly as their parents or elders before them (Kothari, 1995). Unless deliberate steps to preserve IK are taken by various concerned and affected communities in developing countries, IK systems in these countries will soon become extinct.

\section{Indigenous knowledge and Africa}

Why didn't Britain ask the Masai to help with the disease? (Ridley, 2001)

Indeed, why did the British not ask the Masai people of Kenya and Tanzania to help with the management of the foot-and-mouth epidemic that caused havoc in their country in 2001? Is it because the knowledge of the Masai people in this respect was seen to be "inferior" and therefore not appreciated by the developed world? Or, is it because this knowledge was not readily and easily accessible?

For generations, Africans have developed IKSs, and these systems, according to Dr Catherine Odora-Hoppers, are

not just about woven baskets and handicraft for tourists per se. They are about excavating the technologies such as looms, textiles, jewellery and brass-work manufacture, exploring indigenous technological 
knowledge in agriculture, fishing, forest resource exploitation, atmospheric management techniques, knowledge transmission systems, architecture, medicine and pharmacology, and recasting the potentialities they represent in a context of democratic participation for community, national and global development in real time (Seepe, 2001).

There are several examples of the application of IK in African communities, including the following:

- In most African communities, despite the availability of Western medicine, people still use medicinal plants, herbs and roots. This specialised knowledge is often known to only a few people, such as village elders, midwives and healers.

- The Masai herdsmen have treated foot-and-mouth disease effectively for generations without resorting to killing the animals (Ridley, 2001).

- The San people of southern Africa have traditionally used stems of the Hoodia, a succulent plant that grows throughout the semi-arid areas of southern Africa, to stave off hunger and thirst when on long journeys, as it acts as an appetite suppressant. The active ingredient in the Hoodia is now being used in the manufacture of a slimming drug (Lund, 2001; Erklärung von Bern, 2001).

- The Fulani people treat cattle ticks using Tephrosia plants (World Bank, 1998).

\subsection{Sharing indigenous knowledge through information and communications technology}

In order for the Web to be relevant to Africa's information needs, culture and environment, it must contain appropriate information content from Africa. Africans themselves can add appropriate content about Africa to the Web. Adding IK would go a long way in ensuring that adequate African content on the Web is accessible to Africans using the Internet. If, however, IK is to be shared and added to the global information infrastructure, it first has to be captured and documented in a format suitable for the $\mathrm{Web}$ - it has to be codified in electronic format. Capturing and documenting IK in Africa, as in other parts of the developing world, presents a number of problems and challenges. Among these are the following:

- Indigenous knowledge is tacit knowledge, i.e. it is mainly held in people's heads. People should be willing to share this knowledge. Generally, communities and/or individuals may not be willing to share their IK with people from outside their community.

- The fact that IK is tacit knowledge also makes it very difficult to record, transfer and disseminate. In a community where providers and recipients speak the same language and share its underlying cultural concepts, IK is much more easily shared than transferring tacit knowledge across cultures (World Bank, 1998).

- For many people, IK means a livelihood. The fact that they alone are the holders of such knowledge puts them at an advantage, and enables them to collect pay for consultations by, for example, farmers, or in the case of healers, the ill (Rouse, 1999). Therefore, such people would see sharing IK as giving up their favourable positions in the community.

- Certain forms of IK cannot be easily transferred to other communities. These forms of IK may rely entirely on a particular community's set of beliefs, religion and spirituality. Outside that community, they may be meaningless and useless. As indicated by Rouse (1999), practices based on beliefs, religion and spirituality are also difficult to document, as they are seemingly based on "irrationality", and cannot be captured in the logic that is required for conventional journals or scientific writing. There are also many problems with understanding the reasons why certain indigenous practices exist.

- There is also the danger of IK being exploited by multinational corporations without the local communities getting any form of compensation or benefit.

\subsection{Documenting Africa's indigenous knowledge}

Every effort should be made to capture and preserve Africa's IKSs that can be documented and shared. Taking into account the fact not all types of IK can be easily captured and documented, efforts should concentrate on documenting good practices that can be transferred across cultures and communities. Africa's IK should be codified in both print and electronic formats, including audio and video formats, in order to make it accessible to a wider community and on the global information infrastructure. IK systems targeting local communities should be made available in the language that those communities understand. Where it is found necessary to share the IK with others, international languages should be used. In addition, databases of IK experts or carriers in various communities should also be developed to act as pointers to experts on various aspects of IK.

Currently, major efforts towards capturing and documenting IK in Africa are a part of larger global projects for the documentation, preservation and sharing of IK being conducted by international organisations. One such project is the World Bank's Indigenous Knowledge Programme. This Programme's website is accessed at http:// 
www.worldbank.org/afr/ik/. The main aim of the site is to facilitate a multilateral dialogue between local communities, NGOs, governments, donors, civil society and the private sector. The ultimate objective of the website is to help mainstream indigenous/traditional knowledge into the activities of development partners and to optimise the benefits of development assistance, especially to the poor (World Bank, 1999). The website is also available in two African languages, Wolof and Swahili.

The website provides access to an IK database at http://www4.worldbank.org/afr/ikdb/ensearch.cfm, which is a collection of indigenous/traditional practices. Users may contribute new cases and comment. A number of records relating to IK in some African countries can be accessed on the database.

\section{Africa's way forward}

Globalisation of Africa's IK can only happen if there is a deliberate approach to capturing, documenting, storing and providing access to such knowledge on the Web. One way of ensuring this is for African countries to set up national IK resource centres. Warren et al. (1993) outline the various functions of such centres, which include:

- Facilitating national and international networking and information exchange

- Documenting IKSs existing within the country in question

- Researching the impact of new circumstances that constrain IK systems

- Designing educational materials for use in universities and in the national institutions that train extension workers, so that more people can learn how to record IKSs

- Establishing documentation units, where recorded systems are stored and made available for use by all those who wish to access IK.

These centres should become the entry points into the country's IKSs. In addition, national IK centres should also be responsible for making available on the Web various types of IK that can be shared across cultures. They should develop national IK portals or gateways to provide access to such knowledge. The Indigenous Knowledge Pages website (http://www.nuffic.nl/ik-pages/addresses.html), updated on 9 November 2001, listed altogether 11 IK resource centres in the following African countries: Burkina Faso, Cameroon, Ghana, Kenya, Madagascar, Nigeria, Sierra Leone and Tanzania. However, none of the centres in the above countries has a website dedicated to IK.

\section{Indigenous knowledge and telecentres}

One way in which access to ICTs and global information content in Africa is being promoted is through the use of telecentres. Telecentres make it possible for local communities in some rural and peri-urban areas to have access to services or facilities such as telephones, faxes, the Internet, word processing and photocopying, with the necessary user support and training. Telecentres in Africa are being implemented mainly with the support of organisations like the United Nations Educational, Scientific and Cultural Organisation (UNESCO), the International Telecommunications Union (ITU), the International Development Research Centre (IDRC), the World Bank, the British Council, the Food and Agriculture Organisation (FAO), the World Health Organisation (WHO), the United Nations Development Programme (UNDP), and many more. Indigenous knowledge systems should be integrated into the activities of telecentres, if these institutions are to serve the information requirements of the local populations. Telecentres should be involved in the collection, processing, storage and dissemination of IK. Access to IK in various formats or media should be made available to those using telecentres, and also on the Internet.

\section{Role of information professionals}

Management of information resources is the responsibility of information professionals, and therefore professionals on the continent have a critical role to play in ensuring that IK is properly harnessed, processed and released. This is only possible if they take a keen interest in the management of this elusive and most difficult resource.

Indigenous knowledge resource centres need to be accessible to locals, and not only researchers and people working on developmental projects. Rouse (1999), citing Water-Bayer (1994: 147), indicates that it is important that these centres do not become "banks" to which only the better educated and economically powerful have access, thus excluding the illiterate and particularly the women. To make a real contribution to rural people's development, these centres must develop and promote approaches to increase rural people's awareness of the indigenous wealth they possess and help them further enrich it. Information professionals can ensure that IK resources held in these centres 
are easily accessible to local populations by ensuring that the centres are open to the general public and accessible via the Web. In addition, information professionals should take a keen interest in developing and establishing telecentres on the continent. Telecentres are among the many ways in which access by the local communities to locally generated content can be ensured. Information professionals should assist in, and contribute to, the acquisition, processing, storage and provision of access to information resources, including IK, in telecentres.

\section{Conclusion}

Contributing to the information content of the Web should not be the monopoly of developed countries only. Africa should also contribute to the information content of the global information infrastructure. This will ensure that people accessing information on the Web have access to information generated and repackaged from Africa. Codifying and making available IK on the Web will go a long way in making a viable contribution. In addition, sharing IK within Africa and with the rest of the world will promote cross-cultural understanding, and give the rest of the world the opportunity to appreciate the richness of African culture and IKSs. Information professionals on the continent have a very important role to play in the globalisation of Africa's IKSs. They should participate in harnessing IK and making it available to users in various formats and media, including the Web. Preservation of IKSs in Africa should be the concern of all Africans, and not only of international organisations and research institutions.

\section{References}

Erklärung von Bern. 2001. Stolen knowledge. [Online]. http://www.evb.ch/index.cfm?page_id=800

Grenier, L. 1998. Working with indigenous knowledge: a guide for researchers. Ottawa: International Development Research Centre.

Ina Hoi Riwa Foundation. 2000. Indigenous knowledge. [Online]. http:/www.geocities.com/yotowawa/ indigenous_knowledge.htm

International Institute of Rural Reconstruction (IIRR). 1996. Recording and using indigenous knowledge: a manual. Silang, Cavite, Philippines: IIRR. [Online]. http://www.panasia.org.sg/iirr/ikmanual/index.htm

Jensen, M. 2001. The African Internet: a status report. [Online]. http://www3.sn.apc.org/africa/afstat.htm

Kothari, B. 1995. From aural to written: the documentation of knowledge in Ecuador. Indigenous Knowledge and Development Monitor, 3(2). [Online]. http://www.nuffic.nl/ciran/ikdm/3-2/articles/kothari.html

Langill, S. 1999. Indigenous knowledge: a resource kit for sustainable development researchers in dryland Africa. Ottawa: International Development Research Centre. [Online]. http://www.idrc.ca/plaw/1 le-IK.html

Lund, C. 2001. San to cash on diet drug deal. The Sunday Times, 18 November, 11.

NUA. 2001. How many online? [Online]. http://www.nua.com/surveys/how_many_online/index.html

Ridley, R. 2001. Why didn’t Britain ask the Masai for help with the disease? The Natal Witness, 6 October.

Rouse, J. 1999. Global dissemination of indigenous knowledge: contradictions, or the way forward? [Online]. http:// www.worldbank.org/afr/ik/global_ik990615.htm

Seepe, S. 2001. Indigenous knowledge systems can benefit everyone. [Online]. http://allafrica.com/stories/200110180385.html

Southern African Research and Documentation Centre (SARDC). n.d. Factsheet No. 9: Indigenous knowledge system. [Online]. http://www.sardc.net/imercsa/zambezi/zfsheet/zfsheet09.html

Warren, D.M., Von Liebenstein, G.W.\& Slikkerveer, L.J. 1993. Networking for indigenous knowledge. Indigenous Knowledge and Development Monitor, 1(1): 2-4. [Online]. http://www.nuffic.nl/ciran/ikdm/1-1/warren_1_s.html

Water-Bayer, A. 1994. The ethics of documenting rural people's knowledge: investigating milk marketing among Fulani women in Nigeria. In Scoones, I., Thompson, J. \& Chambers, R. (Eds), Beyond farmer first: rural people's knowledge, agricultural research and extension practice. London: Intermediate Technology Publications, 144-147.

World Bank. 1998. Indigenous knowledge for development: a framework for action. [Online]. http://www.worldbank.org/afr/ik/ ikrept.pdf

World Bank. 1999. Indigenous knowledge for development. [Online]. http://www.worldbank.org/afr/ik/broch.pdf 
information, however, tends to be mediated by the researchers' interpretations, and may occasionally not capture the most fundamental and profound meanings of indigenous knowledge and practices of indigenous people themselves. It is also often the case that once raw data has been used in a specific research project, such data is rarely kept for use by other research projects by the same or other researchers, leading to a loss of unique and valuable knowledge. As a result, there is a need for an alternative approach to the capturing, organisation and dissemination of indigenous information in order to preserve its originality and authenticity. Such an approach would not replace the other methods of acquiring information as in research projects, but will seek to provide supplementary information where it is felt that a gap exists. In addition to describing setting up processes of an Information Resource Centre, therefore, the paper also attempts to highlight this alternative approach to capturing Indigenous Knowledge within the framework of an established Information Resource Centre at Harry Oppenheimer Research Centre (HOORC) of the University of Botswana.

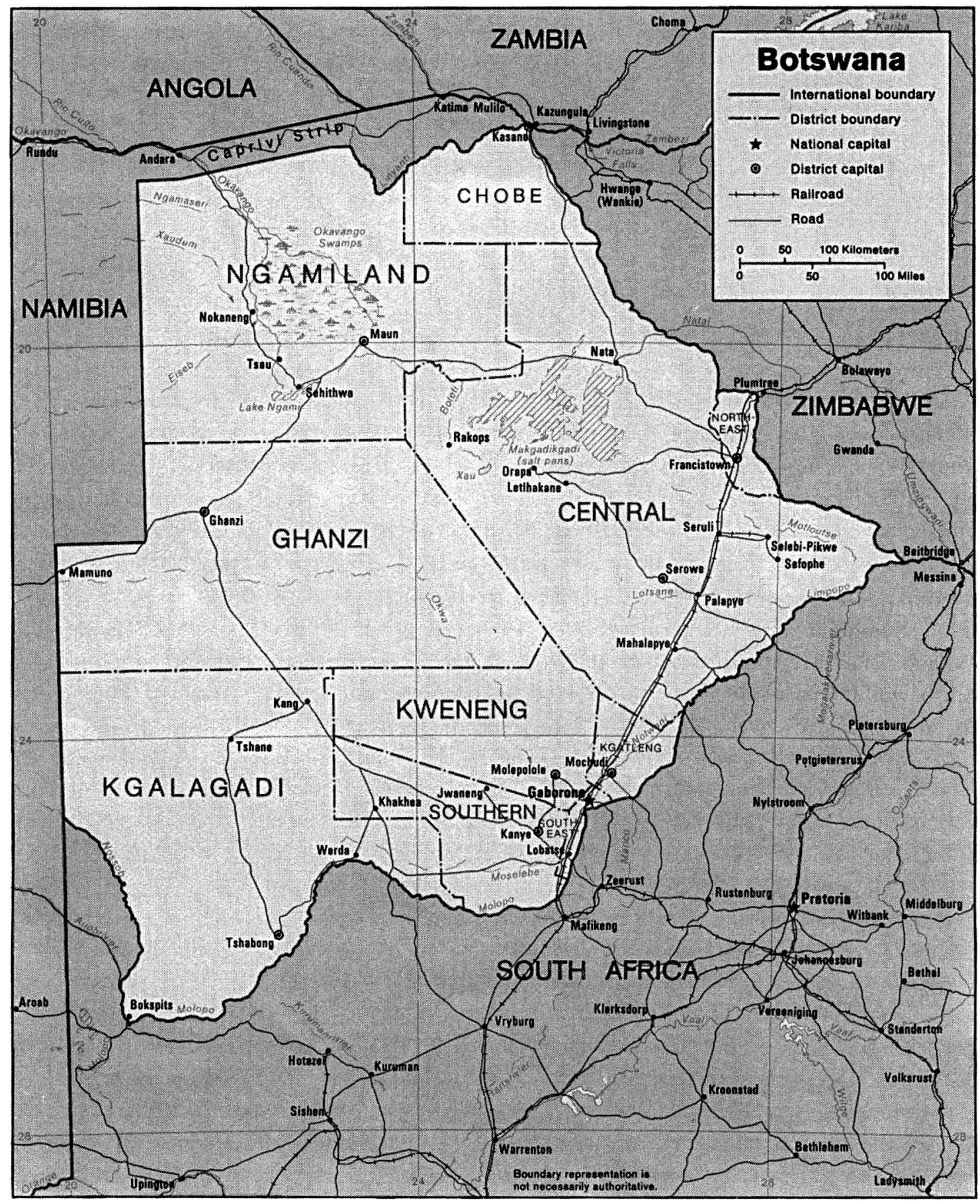

Figure 1 Map of Botswana 